\title{
Regional lung clearance during cough and forced expiration technique (FET): effects of flow and viscoelasticity
}

\author{
A Hasani, D Pavia*, J E Agnew, S W Clarke
}

\begin{abstract}
Background - In vitro studies have suggested that both the viscoelastic properties of lung secretions and the peak flow attained during simulated cough influence clearance. This study examines the possible association of the viscoelastic properties of sputum and maximum expiratory flow with measured effectiveness of mucus clearance induced by instructed cough and by forced expiration technique (FET) in patients with airways obstruction.

Methods - Nineteen patients (11 men and eight women) of mean (SE) age, \% predicted $F E V_{1}$, and daily sputum wet weight of 64 (2) years, $52(6) \%$, and $37.5(7.9) \mathrm{g}$ respectively participated in the study. Mucus movement from proximal and peripheral lung regions was measured by an objective non-invasive radioaerosol technique. Each patient underwent three assessments: control, cough, and FET. During cough and FET, maximum expiratory flow was measured at the mouth level. Apparent viscosity and elasticity of the expectorated sputum samples were measured with a viscometer.
\end{abstract}

Results - Compared with the control run (mean (SE) clearance: $16(3) \%$ ) there was an increase in clearance from the whole lung during cough (44 (5)\%) and FET (42 (5)\%), and also an enhanced clearance of inhaled, deposited radioaerosol from the trachea, inner and intermediate regions of the lungs, but not from the outer region. There were, however, no differences in regional clearance between cough and FET. Neither regional nor total clearance correlated with maximum expiratory flow, apparent viscosity, elasticity, or daily sputum wet weight.

Conclusions - These results confirm that cough and FET both promote effective clearance but suggest that, unlike in vitro studies, sputum production and viscoelasticity, as well as maximum expiratory flow, provide no guide to clearance efficacy in humans.

(Thorax 1994;49:557-561)

Cough is a reserve defence mechanism for removal of lung secretions. ${ }^{1}$ It is particularly important as a back-up mechanism in airway diseases where mucociliary transport - the primary host defence mechanism for mucus clearance - is often compromised. ${ }^{23}$ In health, cough comes into action during emergency situations such as following the inhalation of a foreign body.

Several studies have addressed the question of the efficacy of cough in clearing inhaled, deposited radioaerosols from the lungs of healthy non-smokers, ${ }^{4-6}$ asymptomatic smokers, ${ }^{7}$ and patients with lung disease. ${ }^{458-14}$ Only four of these studies examined the effectiveness of cough in clearing lung secretions on a regional basis from the lungs..$^{8-1014}$ The other studies considered effectiveness only for mucus clearance from the lungs as a whole. The regional clearance studies have given conflicting evidence as to the effectiveness of cough in peripheral regions of the lungs.

The forced expiratory technique (FET) or "huffing" was introduced by physiotherapists as an alternative to coughing for the removal of excess lung secretions. ${ }^{15}$ Its introduction was based on the claim that it reduces transpulmonary pressure compared with cough, thereby resulting in less airway compression and closure. ${ }^{16}$ Its effect on mucus clearance from the lungs as a whole using radioaerosols has been studied in patients with hypersecretion. ${ }^{11}$

We now report a study on the effect of cough and FET on regional mucus clearance in a group of patients with airways disease and varying amounts of daily sputum production. This study also examined the possible association between cough/FET and the maximum expiratory flow attained during these manoeuvres, the viscoelasticity of the expectorated secretions, and a measure of hypersecretion in these patients.

\section{Methods}

\section{PATIENTS}

Nineteen patients (11 men, eight women) with a mean (SE) age of 64 (2) years participated in the study. Twelve patients (six women) had chronic obstructive pulmonary disease (COPD) and seven (two women) had bronchiectasis. Fifteen patients were on inhaled bronchodilators of whom eight were also taking oral bronchodilator therapy, and 12 were maintained with inhaled corticosteroid therapy (one of them was also taking oral corticosteroids). One patient was on home nebuliser bronchodilator therapy and four patients (two 
COPD and two bronchiectasis) were on no medication. The mean (range) increase in $\mathrm{FEV}_{1}$ following the administration of two puffs $(100 \mu \mathrm{g}$ each) of salbutamol was 9 (0$40) \%$. The group comprised four non-smokers with bronchiectasis, two current smokers with COPD (46 and 68 pack-years), and $13 \mathrm{ex}-$ smokers with a mean (SE) of 31 (4) pack-years. The mean (SE) daily sputum wet weight production for the group was $37 \cdot 5(7 \cdot 9) \mathrm{g}$.

\section{STUDY DESIGN}

The study was designed in a randomised, three way, crossover (within patients) manner. Each patient attended our laboratories on three occasions separated by at least three days. During each visit the patient underwent an identical experimental procedure but performed one of three treatment manoeuvres. These manoeuvres were cough, FET, and control which were all carried out with the patient sitting in the upright position. During the cough manoeuvre the patient was instructed to perform six coughs (each cough after full inspiration) per minute, repeated five times, with a rest period of one minute between each series of six coughs. During the FET manoeuvre the patient was instructed to perform six forced expirations per minute with the glottis open, starting from approximately mid lung volume and ending the exhalation close to residual volume, for five minutes with one minute rest period after every six forced expirations. During the control manoeuvre the patient just rested with no coughs or forced expirations.

Maximum expiratory flow during the cough and FET manoeuvres was measured at the mouth using a Vitalograph Compact spirometer which employed a Fleisch type pneumotachograph. The mean value of the maximum expiratory flows measured for the 30 coughs or FETs was calculated for each patient.

The patients were asked to refrain from taking any inhaled bronchodilators for at least two hours before each visit to the laboratories.

Informed written consent was obtained from all the patients and the study was approved by the hospital's Ethical Practices Subcommittee.

\section{RADIOAEROSOL TECHNIQUE}

An objective radioaerosol technique, which has previously been described in detail, was used to assess movement of mucus within the patients' lungs. ${ }^{17}{ }^{18}$ Polystyrene particles $(5 \mu \mathrm{m}$ in diameter) labelled ${ }^{19}$ with technetium-99m were inhaled under controlled conditions through the mouth. Each patient, while seated and wearing a nose clip, inhaled discrete breaths $(0.45$ litre) from the resting level of the lungs followed by a three second breath hold pause in order to enhance deposition of the radioaerosol in the peripheral airways of the lungs. ${ }^{20}$ The patient gargled and drank some water after inhaling the radioaerosol to clear any deposited particles from the oropharynx and oesophagus. Two axially opposed, collimated scintillation detectors located anteroposteriorly to the chest were used to ascertain the radioactivity present in the lungs immediately after inhaling the radioaerosol and 24 hours later. The 24 hour particle retention was expressed as a percentage of the initial value after being corrected for background radiation and physical decay of the radionuclide and was taken to represent "alveolar deposition" within the lungs. ${ }^{21}$

\section{REGIONAL CLEARANCE}

A large field-of-view gamma camera (Ohio Nuclear-110) linked to a computer (Nuclear Diagnostics) was used to assess the initial topographical distribution and subsequent clearance of the radioaerosol particles from the lungs. The initial distribution of the particles was expressed quantitatively as a penetration index which is the ratio of the amount of radioaerosol in an outer to inner region of the lungs divided by the same ratio for krypton$81 \mathrm{~m}$ gas. ${ }^{22}$ The measurement of the radioaerosol clearance was based on dividing the gamma camera images $(64 \times 64$ format $)$ of the lung into four arbitrary regions (fig 1 ). The four regions were a tracheal region which comprised mainly the trachea, an inner region which comprised mainly large airways, and intermediate and outer regions which comprised mainly small airways. A posterior ${ }^{81 \mathrm{~m}} \mathrm{Kr}$ ventilation image was taken for each patient to assess the outer edges of the lungs (15\% and $30 \%$ contours), and was adjusted to align with the aerosol images. A $5 \times 8$ matrix was fitted as closely as possible to the outer contours of the ${ }^{81 \mathrm{~m}} \mathrm{Kr}$ image to define the four regions of the lung. ${ }^{23}$ The regional clearance of the radioaerosol particles was corrected for alveolar deposition and inter-regional movement.

Images of the distribution of the radioaerosol particles within the lungs were taken immediately before and after each of the three treatment manoeuvres which were commenced within 10-15 minutes after the radioaerosol inhalation.

\section{RHEOLOGICAL PROPERTIES OF SPUTUM}

The patients were provided with containers and instructed to collect all sputum produced over a 24 hour period before each visit. The daily sputum production for each patient was described by the mean wet weight for the three sputum collections. All sputum samples expectorated during the cough and FET manoeuvres were collected and the wet weight was ascertained.

The viscoelastic properties - that is, apparent viscosity $(\eta)$ in $\mathrm{mPa} \cdot \mathrm{s}$ and elasticity $\left(\mathrm{G}^{\prime}\right)$ in $\mathrm{mPa}$ - were measured only in sputum samples collected during the cough and FET manoeuvres. A Contraves Low Shear 30 Sinus viscometer was used, ${ }^{24}$ and measurements were taken at a frequency of $0.325 \mathrm{~Hz}$ and a temperature of $37^{\circ} \mathrm{C}$. Whenever possible, three samples of $1 \mathrm{ml}$ in volume were tested within one hour of production for each patient and the results were expressed as the mean. 


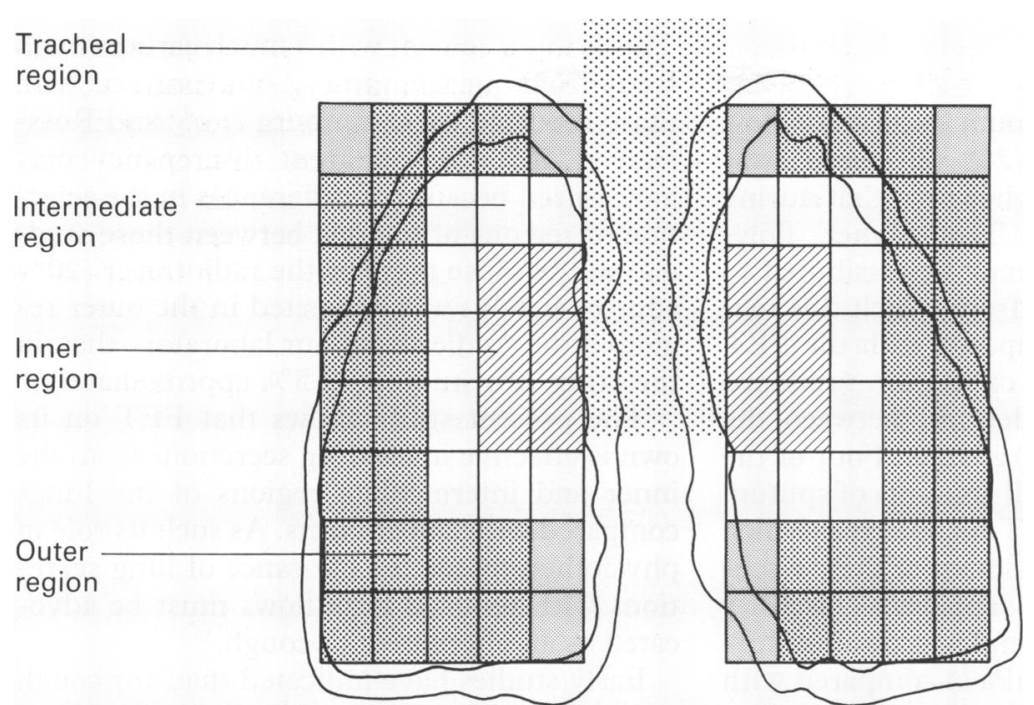

Figure 1 Definition of four regions relative to contours (15\% and $30 \%)$ of ${ }^{81 \mathrm{~m}} \mathrm{Kr}$ ventilation image. between the three runs. Mean (SE) alveolar deposition was $24(2) \%, 25(2) \%$, and $24(2) \%$, and penetration index was $0.38(0.05), 0.39$ $(0.05)$, and $0.39(0.04)$ for the control, cough, and FET runs respectively. Figure 2 shows the percentage of initial tracheobronchial deposition of the radioaerosol in the four regions of interest of the lungs for the three runs. The distribution for any one region between the three runs was similar.

Tracheobronchial clearance from the lungs as a whole measured with the scintillation detectors showed that clearance was significantly enhanced $(\mathrm{p}<0.01)$ following cough $(44$ (5)\%) and FET (42 (5)\%) compared with control during which the patients did not cough $(16(3) \%)$. Following the pulmonary function tests (which themselves involved nine forceful expiratory manoeuvres) tracheobronchial clearance was significantly faster $(\mathrm{p}<0.05)$ for the control run $(22(4) \%)$ compared with both cough $(10(1) \%)$ and FET (9 (2)\%).

Figure 3 illustrates the regional tracheobronchial clearance for the manoeuvres. Cough and FET significantly enhanced clearance of radioaerosol from the trachea, inner, and middle regions of interest of the lungs, but not from the outer region. There were, how-

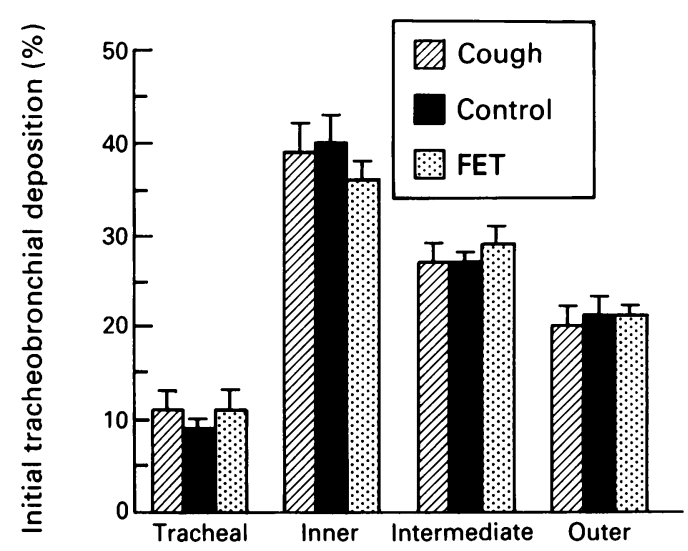

Figure 2 Mean (SE) initial tracheobronchial deposition of the radioaerosol within the four regions of the lungs for the three study days.

\section{Results}

The mean (SE) pulmonary function indices for the patients during the three visits are given in table 1. Pulmonary function remained unchanged between the visits.

The initial topographical distribution of the radioaerosol within the lungs was similar

Table 1 Mean (SE) \% predicted pulmonary function indices for the patients during the three study visits

\begin{tabular}{|c|c|c|c|}
\hline Pulmonary function indices & Control & Cough & $F E T$ \\
\hline $\begin{array}{l}\text { FEV } \\
\text { FVC } \\
\text { PEF } \\
\text { MMF }_{25-75} \\
\dot{\operatorname{Vmax}} \max _{50} \\
\operatorname{Vmax}_{25}\end{array}$ & $\begin{array}{l}50(5) \\
69(5) \\
50(5) \\
28(5) \\
22(4) \\
24(5)\end{array}$ & $\begin{array}{l}53(5) \\
73(4) \\
53(5) \\
29(6) \\
21(4) \\
24(4)\end{array}$ & $\begin{array}{l}52(6) \\
71(5) \\
52(5) \\
28(5) \\
23(4) \\
25(4)\end{array}$ \\
\hline
\end{tabular}

$\mathrm{FEV}_{1}=$ forced expiratory volume in one second; $\mathrm{FVC}=$ forced vital capacity; $\mathrm{PEF}=$ peak expiratory flow rate; $\mathrm{MMF}_{25-75}=$ maximum mid expiratory flow rate; $\operatorname{Vmax}_{50}$ and $\mathrm{Vmax}_{25}=$ flow rates at $50 \%$ and $25 \%$ of vital capacity.

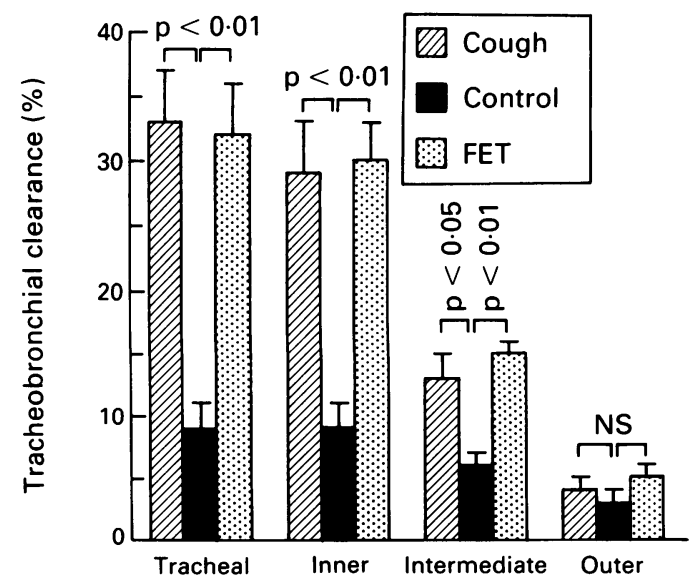

Figure 3 Mean (SE) tracheobronchial clearance of the radioaerosol from the four regions of the lungs during the three manoeuvres. 
ever, no differences in regional clearance between cough and FET.

The mean (SE) maximum expiratory flow recorded during cough (288 (29) $1 / \mathrm{min})$ was significantly $(\mathrm{p}<0.01)$ higher than that during FET (203 (25) l/min). The higher flows measured during cough may be attributed to the higher lung volumes from which this manoeuvre commenced compared with the FET manoeuvre. The amount of sputum produced under instruction was identical between the cough and FET $(3.4(0.5) \mathrm{g})$ runs. Four of the 19 patients produced small amounts of sputum during the cough and FET manoeuvres which were insufficient for assessment of their viscoelastic properties. The apparent viscosity values for the sputum samples produced during the cough $(693(78) \mathrm{mPa} \cdot \mathrm{s})$ compared with FET (684 (106) $\mathrm{mPa} \cdot \mathrm{s}$ ) runs were similar, as were the elasticity values $(2979(503) \mathrm{mPa} v$ $3054(560) \mathrm{mPa}$ respectively).

There was no correlation between regional clearance and any of the following: maximum expiratory flow attained during the manoeuvres, the apparent viscosity and elasticity of sputum (fig 4), the amount of sputum expectorated during the manoeuvres, and the daily sputum production of the patients before the study. Table 2 gives the correlation coefficients for the comparison between clearance from the four regions of interest of the lungs and apparent viscosity and elasticity of sputum and maximum expiratory flow.

\section{Discussion}

Our observations of an enhancement of whole lung radioaerosol clearance following instructed cough confirm previous observations reported by other workers on smaller numbers of patients. ${ }^{4511}$ Furthermore, the enhancement of whole lung radioaerosol clearance following FET is in keeping with the observations of Sutton and coworkers. ${ }^{11}$

On theoretical grounds and using Weibel's model of the human lung Leith ${ }^{28}$ postulated that cough may be effective in clearing secretions from the trachea down to the seventh or eighth airway generation. Scherer, ${ }^{29}$ however, using an in vitro model, suggested that cough in the presence of hypersecretion may be effective in clearing secretions from airways as far as the respiratory bronchioles. Our data on regional clearance show that cough is effective in clearing secretions from the inner and intermediate regions, in keeping with observations from other published data. However, clearance of secretions from the outer region due to cough failed to attain statistical significance.

Table 2 Spearman correlation coefficients $\left(r_{\mathrm{s}}\right)$ for comparison between clearance $(\%)$ from the four regions of the lungs and apparent viscosity and elasticity of sputum and maximum expiratory flow during cough and FET

\begin{tabular}{|c|c|c|c|c|}
\hline & $\begin{array}{l}\text { Tracheal } \\
\text { (Cough/FET) }\end{array}$ & $\begin{array}{l}\text { Inner } \\
\text { (Cough/FET) }\end{array}$ & $\begin{array}{l}\text { Intermediate } \\
\text { (Cough/FET) }\end{array}$ & $\begin{array}{l}\text { Outer } \\
\text { (Cough/FET) }\end{array}$ \\
\hline $\begin{array}{l}\text { Viscosity ( } \eta \text { ) } \\
\text { Elasticity (G') } \\
\text { Maximum flow }\end{array}$ & $\begin{array}{l}-0.24 /-0.34 \\
-0.09 /-0.31 \\
-0.18 / 0.01\end{array}$ & $\begin{array}{l}-0.05 /-0.19 \\
0.004 /-0.25 \\
-0.01 / 0.07\end{array}$ & $\begin{array}{l}0.27 /-0.11 \\
0.40 /-0.01 \\
-0.26 / 0.21\end{array}$ & $\begin{array}{l}-0.01 /-0.14 \\
0 \cdot 10 /-0 \cdot 25 \\
-0 \cdot 28 / 0 \cdot 18\end{array}$ \\
\hline
\end{tabular}

$\mathrm{p}$ not significant for all regions.
This is in agreement with a much earlier cough study from our laboratory, ${ }^{8}$ but contrasts with those reported by Oldenburg et $a l^{9}$ and Rossman et al. ${ }^{10}$ The apparent discrepancy may have arisen because of differences in the selection of regions of interest between those studies, and because more of the radiotracer $(20 \%$ approximately) was deposited in the outer region in the studies from our laboratory than in the other two studies (12.5\% approximately).

The present study shows that FET on its own is effective in clearing secretions from the inner and intermediate regions of the lungs compared with control runs. As such its role in physiotherapy for the clearance of lung secretions with reduced peak flows must be advocated as an alternative to cough. ${ }^{30}$

Early studies have indicated that, for cough to be effective in clearing inhaled radioaerosol from the lungs, the presence of hypersecretion is essential. ${ }^{45}$ More recently Bennett $e t$ al have shown a small improvement in whole lung clearance following 60 controlled coughs over a one hour period in healthy subjects, ${ }^{6}$ but not in a group of asymptomatic smokers. ${ }^{7}$ The number of coughs used by Bennett et al were far in excess of those used by other investig-
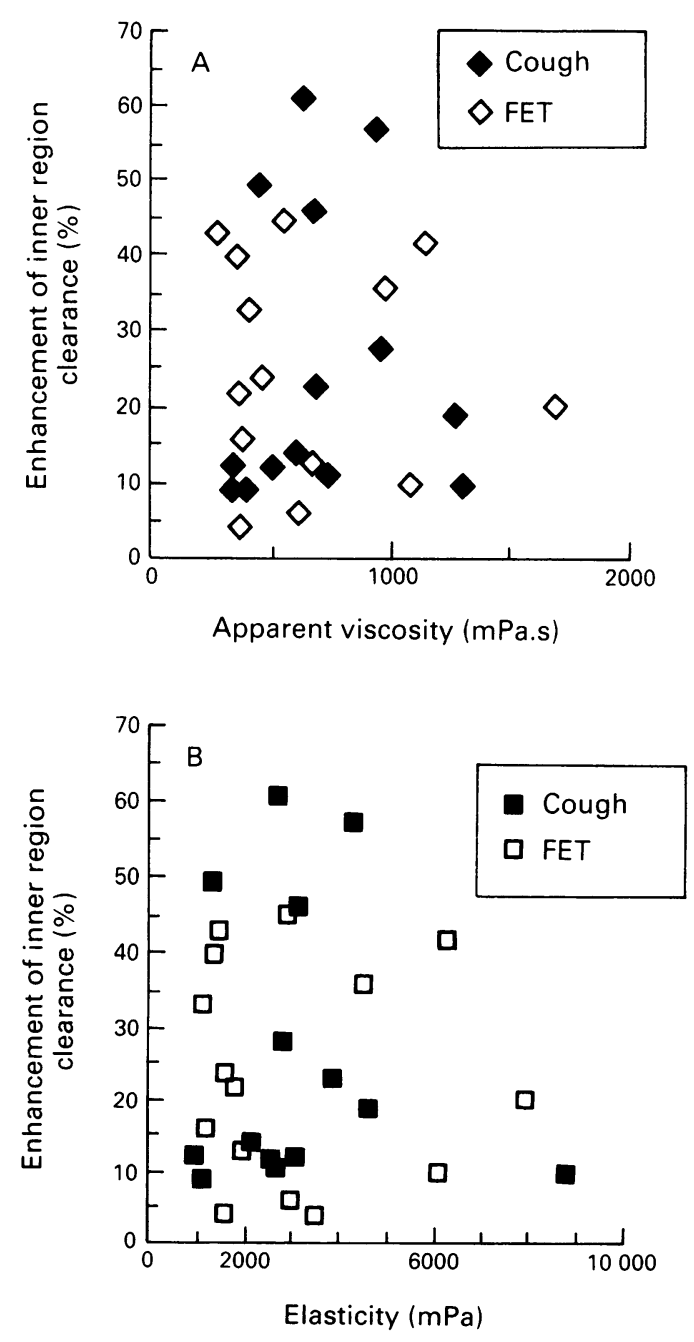

Figure 4 Enhancement of inner region clearance following cough and FET over control for the study group compared with $(A)$ apparent viscosity and (B) elasticity of sputum expectorated during these manoeuvres. 
ators. Mucus clearance by cough and FET in our study was not correlated with the amount of sputum produced during the forceful expiratory manoeuvres, nor with the daily sputum production of the patients which was taken to be a rough guide of their hypersecretory state.

The enhanced clearance during the pulmonary function testing (which required nine forceful expiratory manoeuvres) in the control run compared with the other two runs was predictable. These exhalatory manoeuvres enhanced the clearance of the excess secretions which were still present in the airways during the control run, whereas in the other two runs instructed cough and FET had already helped to expel the excess secretions.

It is acknowledged that sputum may not be representative of the quality and quantity of mucus in the airways. Nevertheless, it serves as an acceptable surrogate. Alternative means of accessing secretions from the airways are invasive and, as such, may in themselves alter the properties of the secretions.

In vitro studies ${ }^{31-33}$ using simulated mucus with apparent viscosity in the range of 1-77 $\mathrm{Pa} \cdot \mathrm{s}$ have suggested that cough is more effective in less viscous material. The lack of a correlation between mucus clearance by cough or FET and viscoelasticity of expectorated secretions in our study may possibly be explained by the fact that the viscosity of the sputum samples ranged over a much narrower "window" (0.3-1.7 Pa.s). The in vitro studies may therefore wrongly predict what actually happens in vivo. The lack of a correlation between mucus clearance by cough or FET and elasticity of expectorated secretions in this study also contrasts with published in vitro studies $^{31}{ }^{32}$ which suggest that elastic forces in the mucus gel impede cough clearance. Clearance stimulated by cough has been reported to be impaired by increases in spinnability and adhesivity of mucus simulants. ${ }^{33}$

Again in vitro studies ${ }^{31} 32$ using mucus simulants have indicated that cough clearance is significantly enhanced with increases in peak flow rate. Our studies in patients do not confirm this and, indeed, show that FET and cough result in similar radioaerosol clearances from the lungs despite a statistically significant reduction (mean $30 \%$ ) in maximum expiratory flow during the former manoeuvre. A possible explanation for this might be that although the maximum flow rates during FET are lower than those attained during cough, their duration could be substantially longer than those for cough and thus make them equally effective in clearing lung secretions.

In conclusion, our study confirms in a substantial number of patients that cough and FET are equally effective in clearing lung secretions, although the latter can be achieved with less effort on the part of the patient. Furthermore, our study indicates the possible risks in extrapolating data from in vitro studies $^{31-33}$ to what actually happens in clinical practice.
1 Hasani A, Pavia D. Cough as a clearance mechanism. In: Braga PC, Allegra L, eds. Cough. New York: Raven Press, 1989:37-52.

2 Wanner A. Clinical aspects of mucociliary transport. $\mathrm{Am}$ Rev Respir Dis 1977;116:73-125.

3 Pavia D. Lung mucociliary clearance. In: Clarke SW, Pavia $\mathrm{D}$, eds. Aerosols and the lung. London: Butterworths, 1984:127-55.

4 Camner P, Mossberg B, Philipson K, Strandberg G. Elimination of test particles from the human tracheobronchial tract by voluntary coughing. Scand $\mathcal{f}$ Respir Dis 1979;60:56-62.

5 Puchelle E, Zahm JM, Girard F, Bertrand A, Polu JM, Aug $\mathrm{F}$, et al. Mucociliary transport in vivo and in vitro. Eur $\mathcal{F}$ Respir Dis 1980;61:254-64.

6 Bennett WD, Foster WM, Chapman WF. Cough enhanced mucus clearance in the normal lung. $f$ Appl Physio 1990;69:1670-5.

7 Bennett WD, Chapman WF, Gerrity TR. Ineffectiveness of cough for enhancing mucus clearance in asymptomatic smokers. Chest 1992;102:412-6.

8 Bateman JRM, Newman SP, Daunt KN, Sheahan NF, Pavia D, Clarke SW. Is cough as effective as chest physiotherapy in removal of excessive tracheobronchial secretions? Thorax 1981;36:683-7.

9 Oldenburg FA, Dolovich MB, Montgomery JM, Newhouse MT. Effect of postural drainage, exercise and cough on mucus clearance in chronic bronchitis. $\mathrm{Am} \mathrm{Rev}$ Respir Dis 1979;120:739-45.

10 Rossman CM, Waldes R, Sampson D, Newhouse MT Effect of chest physiotherapy on the removal of mucus in patients with cystic fibrosis. Am Rev Respir Dis 1982;126:131-5.

11 Sutton PP, Parker RA, Webber BA, Newman S, Garland $\mathrm{N}$, Lopez-Vidriero $\mathrm{M}$, et al. Assessment of the forced expiration technique, postural drainage and directed coughing in chest physiotherapy. Eur $\mathcal{f}$ Respir Dis 1983;64:62-8.

12 Agnew JE, Little F, Pavia D, Clarke SW. Mucus clearance from the airways in chronic bronchitis, smokers and exsmokers. Bull Eur Physiopathol Respir 1982;18:473-84.

13 Agnew JE, Bateman JRM, Sheahan NF, Lennard-Jones AM, Pavia D, Clarke SW. Effect of oral corticosteroids on mucus clearance by cough and mucociliary transport in stable asthma. Bull Eur Physiopathol Respir 1983;19:3741.

14 Hasani A, Pavia D, Agnew JE, Clarke SW. The effect of unproductive coughing/FET on regional mucus movement in the human lungs. Respir Med 1991;85:23-6.

15 Thompson BJ. The physiotherapist's role in the rehabilitation of the asthmatic. NZ $\mathcal{F}$ Physiother 1973;4:11-6.

16 Langlands $J$. The dynamics of cough in health and in chronic bronchitis. Thorax 1967;22:88-96.

17 Thomson ML, Short MD. Mucociliary function in health, chronic obstructive airway disease, and asbestosis. $\mathcal{F} \mathrm{Appl}$ Physiol 1969;26:535-9.

18 Pavia D, Sutton PP, Agnew JE, Lopez-Vidriero MT, Newman SP, Clarke SW. Measurement of bronchial mucociliary clearance. Eur $\mathcal{F}$ Respir Dis 1983;64:41-56.

19 Few JD, Short MD, Thomson ML. Preparation of ${ }^{99 \mathrm{~m} T \mathrm{c}}$ labelled particles for aerosol studies. Radiochem Radioanal Lett 1970;5:275-7.

20 Newman SP, Pavia D, Moren F, Sheahan NF, Clarke SW. Deposition of pressurized aerosols in the human respiratory tract. Thorax 1981;36:52-5.

21 Camner P, Philipson K. Human alveolar deposition of $4 \mu \mathrm{m}$ teflon particles. Arch Environ Health 1978;36:181-5.

22 Agnew JE, Pavia D, Clarke SW. Airways penetration of inhaled radioaerosol: an index to small airways function. Eur $\mathcal{F}$ Respir Dis 1981;62:239-55.

23 Agnew JE, Bateman JRM, Pavia D, Clarke SW. A model for assessing bronchial mucus transport. $f$ Nucl Med 1984;24:170-6.

24 Pavia D, Lopez-Vidriero MT, Agnew JE, Taylor RG, Eyre-Brook A, Lawton WA, et al. Effect of four-week treatment with oxitropium bromide on lung mucociliary clearance in patients with chronic bronchitis or asthma. Respiration 1989;55:33-43.

25 Cotes JE. Lung function: assessment and application in medicine. 4th ed. Oxford: Blackwell, 1979.

26 Knudson RJ, Lebowitz MD, Holberg CJ, Burrows B. Changes in the normal maximal expiratory flow volume curve with growth and aging. Am Rev Respir Dis 1983;127:725-34

27 Siegel S. Nonparametric statistics for the behavioral sciences. Tokyo: McGraw-Hill, 1956

28 Leith DE. Cough. Phys Ther 1968;48:439-47.

29 Scherer PW. Mucus transport by cough. Chest 1982;80:830-3.

30 Pryor JA, Webber BA, Hodson ME, Batten JC. Evaluation of the forced expiration technique as an adjunct to posof the forced expiration technique as an adjunct to pos-
tural drainage in the treatment of cystic fibrosis. BMF tural drainage

31 King M, Brock G, Lundell C. Clearance of mucus by simulated cough. F Appl Physiol 1985;58:1776-82.

32 King $M$. The role of mucus viscoelasticity in cough clearance. Biorheology 1987;24:589-97.

33 King M, Zahm JM, Pierrot D, Vaquez-Girod S, Puchelle E. The role of mucus gel viscosity, spinnability, and adhesive properties in clearance by simulated cough. Biorheology 1989;26:737-45. 